\title{
English-Arabic-English Translation: A Novel Methodological Framework for the Standardisation of Translation Parameters
}

\author{
Ahmad Mustafa Halimah ${ }^{1}$ \\ ${ }^{1}$ King Faisal University, AlAhsa, Saudi Arabia \\ Correspondence: Ahmad Mustafa Halimah, Associate Professor of Applied Linguistics and Translation Studies, \\ Department of English Language \& Literature, College of Arts, King Faisal University, AlAhsa, Saudi Arabia. \\ E-mail: ahalimah@kfu.edu.sa
}

Received: May 15, 2020 Accepted: June 18, 2020 Online Published: June 23, 2020

doi:10.5539/ells.v10n3p15 URL: https://doi.org/10.5539/ells.v10n3p15

\begin{abstract}
It is evident to see that, in the field of translation, there is a random use of the terms 'method', 'approach', 'strategy', 'procedure' and 'technique' by both teachers and students alike. This article attempts to shed light on such phenomenon and to bring more clarity and objectivity to the world of translation by suggesting a standardised methodological framework. English-Arabic-English translation examples and a questionnaire filled by university Arabic-speaking students and teachers were used for analysis and discussion. Results of the analysis and discussion of samples and the questionnaire in this paper have indicated that there is an urgent need for a novel methodological framework in order to form a standardised profile for the use of translation parameters such as 'method', 'approach', 'strategy', 'procedure' and 'technique'. To achieve this objective, a proposed methodological framework was made for use by students, teachers and those interested in carrying out further research in this field.
\end{abstract}

Keywords: translation, 'method', 'approach', 'strategy', 'procedure' and 'technique', methodological framework

\section{Introduction}

There has been a lot of debate over the terminology used to analyse translations and practise translation as an interlingual phenomenon. Confusion seems to surround the concepts and usage of the following five most common translation parameters: Method, Approach, Strategy, Procedure and Technique. Cicero (46 BC) and St. Jerome (395 CE), for example, did not use any of the five parameters but referred to the process and product of translation by the generic term 'translation' to inform readers about the kind of translation they used as 'word-for-word' translation and 'sense for sense' translation. These two poles identified by Cicero (46 BC) and St. Jerome (395 CE) were replaced with 'literal translation' and 'free translation' respectively during the Abbasid Age (750-1258), by two well-known translators: Yuhanna bin Batriq' who used 'literal' translation and Hunayn bin Ishaq's who used 'free' translation (Gutas, 1998).

In the second half of the twentieth century, there was a change where Eugen Nida (1964a), for example, used the terms 'formal equivalence' and 'dynamic equivalence' as concepts to refer to the phenomenon of translation rather than any one of the aforementioned five parameters. Similarly, in his linguistic approach to translation, Catford (1965) used the term 'translation shift' instead of the five parameters (Jeremy, 2001/2008). Peter Newmark, however, in his dichotomy of language translation emphasis, (1988, p. 45) truly pioneered in his use of the parameter 'method', to refer to the following terms of Source Language (SL) translation emphasis: 'word-for-word', 'literal', 'faithful' and 'semantic', and those of the Target Language (TL) emphasis, 'adaptation', 'free', 'idiomatic' and 'communicative'. It must also be noted that while he related the 'translation methods' to whole texts, he also used the term 'procedure' to refer to 'sentences and the smaller units of language' (Ibid, p. 81) as in the following examples: 'transference', 'naturalisation', 'transposition', 'modulation' etc...

Unlike Newmark (1988), Vinay and Darbelnet (1995, pp. 30-42) identified two major methods: 'direct translation' and 'oblique translation'. They, however, referred to them as strategies and associated the former with three procedures called "borrowing, calque, and literal translation" and the latter with four procedures called "transposition, modulation, equivalence and adaptation". This said, their use of terminology lacked a rigorous and systematic use of such terms. 
Although Schleiermarcher, in his essay "on the Different Methods of Translation" (1813), pointed out that there are only two methods of translation (alienating or naturalising), Venuti (1995, pp. 3-35), in his book, "The translator's Invisibility", was the first to rigorously dichotomise translation approaches into two, naming the first a foreignising approach and the second a domesticating approach. Loosely, Ghazala (2014, p. 156) used the term 'Methods of Arabisation' to refer to the use of 'transcription', 'naturalisation', and 'translation by omission' as means to the translation of technical terms into Arabic.

Essentially, the list of terms used in translation is quite long, loose and abundant. Such a situation makes learning and teaching translation in an Arabic context challenging, and even potentially confusing, as the terms employed in the field lack consistency which consequently makes them unscientific and subjective. This paper attempts to shed light on this phenomenon by using English-Arabic-English translation examples and a questionnaire filled by university Arabic speaking teachers and students. It will also attempt to bring more clarity and objectivity to the world of translation by suggesting a novel standardised methodological framework.

\section{Theoretical Considerations}

One of the most interesting attempts made to review the definitions and classifications of translation techniques was by Molina and Albir, article (2002) entitled Translation Techniques Revisited: A Dynamic and Functionalist Approach. In this article, they reviewed different approaches to classifying translation techniques such as those used by Vinay and Darbbelnet's (SCFA) (1958), Bible translators such as Nida's (1964) Techniques of Adjustment (addition, subtractions and alterations), Delisle's (1993) introduction of a different terminology such as translation strategies, translation errors but maintained the term procedure proposed by Vinay and Darbelnet's (1995) proposals. And yet, although they asserted the problems and difficulties caused by the diversity of terminology employed, and the overlapping nature of terms used in the analysis and production of translation, they failed to provide a comprehensive methodological framework with certain pedagogical applications. Furthermore, in their proposed classification of translation techniques, they used only two Arabic examples, which would be unsuitable for teaching English-Arabic-English translation. This being so, they did, however, successfully distinguished between terms such as method, strategies and techniques as 'essentially different categories' and proposed the word 'technique' as a generic term to cover a long list of instruments used differently in the analysis of translation.

Ordudari (2007) presents us with different definitions of translation procedures, strategies and methods by a number of translation theorists: Nida's (1964) definition of 'procedures', Krings (1986) and Lörscher (1992), Bell (1998) Venuti (1998) definitions of 'strategies' and Newmark's (1988) definition and differentiation of both method and procedure. He did not give any examples of the application of the terms. Similarly, Zohre Owji (2013) provides us with a detailed description and explanation of the term 'strategies' but his work is void of any practical examples or pedagogical implications or guidelines.

In her article "Translating Culture: Problems, Strategies and Practical Realities", Guerra (2012) reviews translation procedures and strategies in literature and points out the differences between the two. She uses the term 'procedure' to refer to a list of 15 debatable mixed translation parameters (procedure, strategy, concept, technique, etc...) in her empirical study of how Spanish students tend to solve cultural problems in translation from English to Spanish and vice versa. Like the aforementioned articles, however, Guerra's article also fails to provide us with a specific methodological framework we can use in processing and producing a translation.

Having made those references, and based on the theoretical considerations mentioned above, I am inclined to use a top-bottom approach to review and redefine the existing translation parameters with special reference to English-Arabic-English Translation. This approach aims to present a standardised conceptual classification of the translation parameters: 'method', 'approach', 'strategy', 'procedure' and 'technique', as a methodological framework which can be used by both students and teachers of translation. In other words, understanding a translation parameter, whether it is a method, an approach, a strategy, a procedure or a technique, tends to determine how translators perceive and carry out a translation. It is due to their importance that the understanding, perception and application of such parameters are the key concerns of this paper.

\subsection{Research Question}

The following question was formed to clarify the notion of the main translation parameters and clear up any confusion over how to use them in English-Arabic-translation:

Do Arabic-speaking students and teachers of translation perceive and use the terms 'method', 'approach', 'strategy', 'procedure' and 'technique' methodologically and appropriately? If not, why not, and how can we amend this issue? 


\section{Methodology}

To achieve the aim of this study, two instruments were used. The first was a questionnaire made to investigate how students and teachers of translation at King Faisal University perceived and used existing parameters of translation ('method', 'approach', 'strategy', 'procedure' and 'technique'). These translation parameters were then redefined to distinguish them from each other and positioned to create a methodological framework that can be used by both students and teachers of translation. A variety of examples from both English and Arabic were used to clarify the notion of the translation parameters in question.

\subsection{Participants}

Students

An aggregate of $10 \mathrm{MA}$ students (5 males and 5 females), doing an MA Programme in Applied Linguistics, at King Faisal University, formed the participants for this study. Arabic is the native language of all the participants who claim to have studied translation courses at undergraduate and postgraduate levels.

\section{Teachers}

Out of a corpus of 25 teachers working at both the English Language Department (ELD) and English Language Centre (ELC) at King Faisal University, 10 (5 males and 5 females) were randomly selected to participate in this study. All of them are PhD holders who have had experience teaching translation to Arabic- speaking students. Arabic is the native tongue of all the participants.

\subsection{Investigation Instruments}

\section{Students' and teachers' questionnaires}

A questionnaire was constructed to find out how students and teachers tend to use translation parameters such as "method, approach, strategy, procedure and technique", in regard to 25 translation topics, when they are translating or teaching translation (see Appendix A). After the questionnaire had been constructed and piloted, it was distributed to $10 \mathrm{MA}$ students and 25 teachers in both the ELD and English LC. The forms were then returned 15 days later. From complete questionnaires, ten were selected to represent students and another ten were selected to represent the teachers.

\section{Translation Examples used}

In order to describe and illustrate the aforementioned translation parameters and translation instruments, different examples were chosen from various text-types and used to build and standardise the process of applying a methodological framework to English-Arabic-English translation.

\section{Data Analysis and Discussion}

The evaluation of the completed questionnaires showed that both students and teachers alike struggled in correctly identifying the appropriate translation parameters (see Table 1).

The questionnaire consisted of 25 translation topics, with five translation parameters matching them. The correct answers were made up of eleven "methods", three "approaches", nine "strategies", one "procedure", and one "technique". 
Table 1. Translation parameters

\begin{tabular}{|c|c|c|c|c|}
\hline Student No. & Male Student Score /25 & $\%$ & Female Student Score /25 & $\%$ \\
\hline 1 & 2 & 8 & 5 & 20 \\
\hline 2 & 4 & 16 & 9 & 36 \\
\hline 3 & 9 & 36 & 10 & 40 \\
\hline 4 & 11 & 44 & 10 & 40 \\
\hline 5 & 11 & 44 & 11 & 44 \\
\hline Mean & 7.4 & 29.6 & 9.0 & 36 \\
\hline Total & 8.2 & & & 32.8 \\
\hline Student No & Male Teacher Score $/ 25$ & $\%$ & Female Teacher Score $/ 25$ & $\%$ \\
\hline 1 & 4 & 16 & 4 & 16 \\
\hline 2 & 6 & 24 & 7 & 28 \\
\hline 3 & 6 & 24 & 9 & 36 \\
\hline 4 & 6 & 24 & 13 & 52 \\
\hline 5 & 10 & 40 & 13 & 52 \\
\hline Mean & 6.4 & 32 & 9.2 & 46 \\
\hline Total & 7.8 & & & 31.2 \\
\hline Combined Mean & 6.9 & 27.6 & 9.1 & 36.4 \\
\hline Total & 8 & & & 32 \\
\hline
\end{tabular}

Across the board, the students and teachers were most successful in recognising the method parameters, with a mean of 5.25 answers correct out of a possible eleven method parameters. This result had the highest level of accuracy throughout the five translation parameters, with 47.7 percent. The students had a greater average than the teachers, with a 61.2 percent mean (6.8) displacing the 33.6 percent mean of the teachers. As shown in Table 2 (below), only one test subject (out of 5 males and 5 females) managed to get all method parameters correct.

Table 2. Method parameter

\begin{tabular}{lllll}
\hline No. & Male Student Score $/ 11$ & $\%$ & Female Student Score $/ 11$ & $\%$ \\
\hline 1 & 1 & 9.1 & 5 & 45.5 \\
2 & 9 & 81.8 & 9 & 81.8 \\
3 & 2 & 18.2 & 7 & 63.6 \\
4 & 9 & 81.8 & 8 & 72.7 \\
5 & 8 & 72.7 & 10 & 90.9 \\
Mean & 5.8 & 52.7 & 7.8 & 70.9 \\
Total & 6.8 & & & 61.2 \\
\hline No. & Male Teacher Score /11 & $\%$ & Female Teacher Score /11 & $\%$ \\
\hline 1 & 0 & 0 & 1 & 9.1 \\
2 & 1 & 9.1 & 2 & 18.2 \\
3 & 3 & 27.3 & 4 & 36.4 \\
4 & 4 & 36.4 & 8 & 72.7 \\
5 & 3 & 27.3 & 11 & 100 \\
Mean & 2.2 & 20 & 5.2 & 47.3 \\
Total & 3.7 & & & 33.6 \\
Combined Mean & 4 & 36.4 & 6.5 & 59.1 \\
Total & 5.25 & & & 47.7 \\
\hline
\end{tabular}

This said, however, the teachers were marginally better than the students in the "approach" parameter column of the questionnaire, where they collectively answered a 0.7 approach parameter score, as opposed to the students' 0.5 average, which evened out to a joint accuracy of 20 percent. Table 3 shows that no students or teachers were successful in correctly answering all three approach parameter questions. 
Table 3. Approach parameter

\begin{tabular}{lllll}
\hline No. & Male Student Score /3 & $\%$ & Female Student Score /3 & $\%$ \\
\hline 1 & 0 & 0 & 0 & 0 \\
2 & 0 & 0 & 0 & 0 \\
3 & 1 & 33 & 0 & 0 \\
4 & 1 & 33 & 2 & 67 \\
5 & 1 & 33 & 0 & 0 \\
Mean & 0.6 & 20 & 0.4 & 13.3 \\
Total & 0.5 & & & 16.7 \\
\hline No. & Male Teacher Score /3 & $\%$ & Female Teacher Score /3 & $\%$ \\
\hline 1 & 0 & 0 & 2 & 67 \\
2 & 1 & 33 & 1 & 33 \\
3 & 0 & 0 & 2 & 67 \\
4 & 0 & 0 & 0 & 0 \\
5 & 1 & 33 & 0 & 0 \\
Mean & 0.4 & 13.3 & 1 & 33 \\
Total & 0.7 & & & 23.3 \\
Combined Mean & 0.5 & 16.7 & 0.7 & 23.3 \\
Total & 0.6 & & & 20 \\
\hline
\end{tabular}

In terms of the "strategy" parameters, which composed over a third of the questionnaire, the teachers considerably outdid the students. This is found where despite their total of 2.7 correct marks per nine parameters, such result is considerably greater than the 0.8 parameter average the students displayed in their answers.

Table 4. Strategy parameter

\begin{tabular}{lllll}
\hline No. & Male Student Score $/ 9$ & $\%$ & Female Student Score $/ 9$ & $\%$ \\
\hline 1 & 0 & 0 & 0 & 0 \\
2 & 0 & 0 & 0 & 0 \\
3 & 2 & 22.2 & 2 & 22.2 \\
4 & 1 & 11.1 & 0 & 0 \\
5 & 2 & 22.2 & 1 & 11.1 \\
Mean & 1 & 11.1 & 0.6 & 6.7 \\
Total & 0.8 & & & 8.8 \\
\hline No. & Male Teacher Score /3 & $\%$ & Female Teacher Score /3 & $\%$ \\
\hline 1 & 3 & 33 & 1 & 11.1 \\
2 & 3 & 33 & 3 & 33 \\
3 & 3 & 33 & 1 & 11.1 \\
4 & 2 & 22.2 & 4 & 44.4 \\
5 & 5 & 55.5 & 2 & 22.2 \\
Mean & 3.2 & 35.6 & 2.2 & 24.4 \\
Total & 2.7 & & & 30 \\
Combined Mean & 2.1 & 23.3 & 1.4 & 15.6 \\
Total & 2.25 & & & 25 \\
\hline
\end{tabular}

The fourth section of the survey was devised of one "procedure" parameter, which, even with answer chances considered, was the lowest 'gross' across the data. Out of the twenty people being studied, only two were successful in categorising the procedure. They were a student and teacher who presented the experiment with a ten percent correct answer rate, across both their testing divides, and the overall participants. 
Table 5. Procedure parameter

\begin{tabular}{lllll}
\hline No. & Male Student Score $/ 1$ & $\%$ & Female Student Score $/ 1$ & $\%$ \\
\hline 1 & 1 & 100 & 0 & 0 \\
2 & 0 & 0 & 0 & 0 \\
3 & 0 & 0 & 0 & 0 \\
4 & 0 & 0 & 0 & 0 \\
5 & 0 & 0 & 0 & 0 \\
Mean & 0.2 & 20 & 0 & 0 \\
Total & 0.1 & & & 10 \\
\hline No. & Male Teacher Score /1 & $\%$ & Female Teacher Score /1 & $\%$ \\
\hline 1 & 0 & 0 & 0 & 0 \\
2 & 1 & 100 & 0 & 0 \\
3 & 0 & 0 & 0 & 0 \\
4 & 0 & 0 & 0 & 0 \\
5 & 0 & 0 & 0 & 0 \\
Mean & 0.2 & 20 & 0 & 0 \\
Total & 0.1 & & & 10 \\
Combined Mean & 0.2 & 20 & 0 & 0 \\
Total & 0.1 & & & 10 \\
\hline
\end{tabular}

The final mark available was that for the singular "technique" parameter, the last part of the questionnaire. Once again, quite a low number of participants managed to correctly grasp the concept, with only three people succeeding. The student 'technique' parameter average was half that of the teachers' and had the question parameter mean at 0.15 , as represented in the below Table 6 .

Table 6. Technique parameter

\begin{tabular}{lllll}
\hline No. & Male Student Score $/ 1$ & $\%$ & Female Student Score $/ 1$ & $\%$ \\
\hline 1 & 0 & 0 & 0 & 0 \\
2 & 0 & 0 & 0 & 0 \\
3 & 0 & 0 & 1 & 100 \\
4 & 0 & 0 & 0 & 0 \\
5 & 0 & 0 & 0 & 0 \\
Mean & 0 & 0 & 0.2 & 20 \\
Total & 0.1 & & & 10 \\
\hline No. & Male Teacher Score /1 & $\%$ & Female Teacher Score /1 & $\%$ \\
\hline 1 & 0 & 0 & 0 & 0 \\
2 & 0 & 0 & 0 & 0 \\
3 & 0 & 0 & 0 & 0 \\
4 & 0 & 0 & 1 & 100 \\
5 & 1 & 100 & 0 & 0 \\
Mean & 0.2 & 20 & 0.2 & 20 \\
Total & 0.2 & & & 30 \\
Combined Mean & 0.2 & 20 & 0.2 & 20 \\
Total & 0.15 & & & 20 \\
\hline
\end{tabular}

With all the data compiled, it became evident that the students performed better than the teachers in completing the questionnaire. As shown in Table 1 above, their overall average of 8.2 parameter marks out of 25 was slightly greater than the teachers' overall score of 7.8 correct parameters. This evened out the scoring across the questionnaire subjects, with eight correct answers out of a possible twenty-five, which is a $32 \%$ correct completion rate.

Regarding gender, the tables differ significantly. The female divide had the larger correct answer average when it came to the "method" parameter column, scoring 6.5 marks as opposed to 4 method parameters. Table 2 above shows that this was 22.7 percent more than that of the male test group.

The female group also achieved a higher average in the "approach" parameter questions, where their 0.7 average outweighed the 0.5 of the male group. This resulted in an overall score of 20 percent accuracy as shown in Table 3 above. 
The "strategy" parameter questions had a different result, with the 2.1 strategy marks (23.3\%) from the male group scoring higher than the females, whose 15.6 percent parameter accuracy (1.4) was only slightly overtaken as shown in Table 4 above.

In the "procedure" parameter column, the female group failed to identify a single instance where a procedure would be an appropriate parameter. The males, however, were able to harvest a small, but noticeably different score, with a 20 percent correct answer accuracy as two test subjects correctly identified the parameter as shown in Table 5 above.

In the final parameter column, once more offering a single mark, the female and male divides scored the same score of a 0.2 "technique" average, which evened out to a combined twenty percent 'technique parameter' accuracy as shown in Table 6.

With the divide between the male and female testing groups still in mind, it is interesting to see how the students and teachers played into the scoring data. The male students scored higher than the male teachers, with a 7.4 parameter average being sixteen percent greater than the 6.4 marks that the teachers raked up. The female teachers, on the other hand, scored a slightly higher result than the female students with a 9.2 parameter average, as opposed to the students' 9 as shown in Table 1 above.

Collectively, all in all there was a male average of 6.9 parameter marks, out of the available 25 . This was less than the average score of the female group, which scored a 9.1 average, a thirty-two percent increase. Using this data basis, the overall parameter mean was then found to be at 8 marks out of a total 25 which gives a thirty-two percent parameter accuracy.

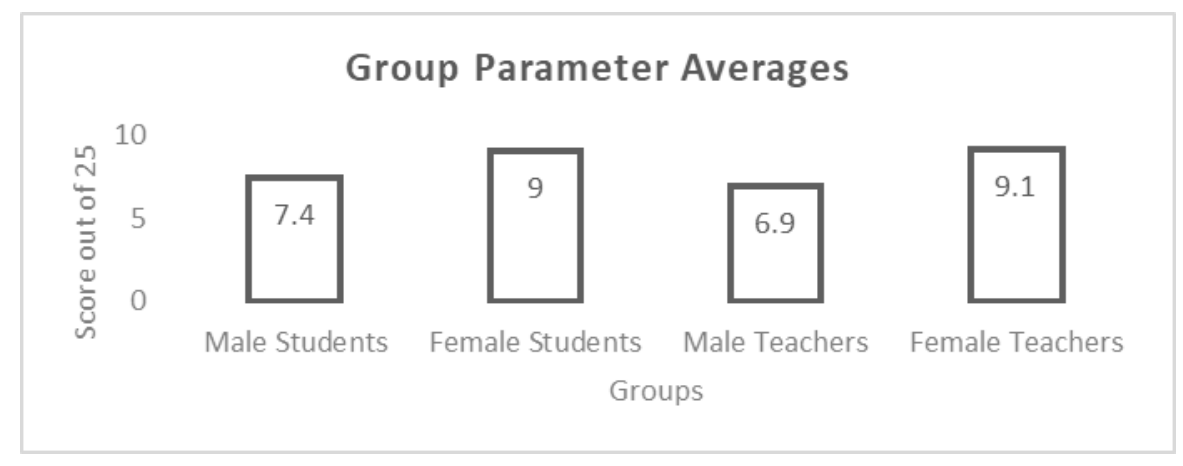

Figure 1. Group parameter averages

\section{Definitions of Translation Parameters}

This paper's proposal is based on the belief that translation's "method, approach, strategy, procedure and technique" are essentially different parameters. Therefore, translators need to distinguish between the use of each of these parameters and adopt a more systematic methodological framework of them at both macro and micro levels translation.

Based on the review of literature and discussion above, the translation parameters "method, approach, strategy, procedure and technique" will be redefined in order to make them more operational terms. They will then be used to propose a translation methodological framework for both Arabic-speaking students and teachers of translation.

- Method is used in this context to refer to the global stance declared by a translator at the very beginning of the translation process of any text. The stance a translator takes affects the translation of the whole text at macro level and micro level and there are several translation methods that can be used. If, for example, a translator decides to emphasise the source language and culture of a text, they can use 'a literal, a faithful, or a semantic method', whereas if they decide to emphasise the target language and culture, they may opt for an 'adaptation, a free, an idiomatic or a communicative method'.

- Approach is used in this context to refer to the local/regional stance declared by a translator after they have decided on the global method. A translation approach is less global and more local when it comes to translating a specific text type as this depends mainly on the translator's main objectives and the purpose of their translation. In other words, after a translator decides on their global method, they are able to narrow 
down their scope of emphasis to make it more specific. There are several translation approaches that can be employed for such purpose. If, for example, a translator's global method is to emphasise the SL and source culture (SC), they can use 'alienating or foreignising', whereas if it is to emphasise the TL and Target Culture(TC), they can use a 'naturalising, or domesticating approach', or any other locally-oriented approach as mentioned below.

- Strategy is used here to refer to an overall translation tactical plan that a translator uses to solve specific problems or overcome potential difficulties when carrying out the translation process. In other words, a strategy is like a saviour for a desperate translator in search for a solution to a specific problem. Difficulties are often encountered in translation regardless of what method or approach is chosen for the task or how experienced or skilful the translator may be. In such cases, there are then a substantial number of strategies that a translator could adopt to aid them in their work such as "borrowing, calque, omission, addition, expansion, modulation, transposition, substitution, transliteration, naturalisation, etc.".

- Procedure, technique and strategy are often "interrelated and used as synonyms" (Guerra, 2012, p. 3). This lack of consensus to agree on the exact meaning of each term causes confusion among students and teachers of English-Arabic-English translation, as seen in the questionnaire results above. Therefore, the terms "procedure and technique" are given little attention if not excluded from the proposal suggested below. Although the term "procedure" is often taken to mean a "strategy" (Vinay and Dalbernet (195/1977), it is used here to refer to the steps a translator takes in executing the translation strategy they are using. If a translator chooses to employ a 'transliteration strategy' to translate a proper name like 'عبداله', for example, they could use the following procedural steps to reach a satisfactory result: selecting a locally oriented approach, like foreignising, deciding on the linguistic and cultural rules of the name, and then executing the translation as follows: عبد اله /Abdullah not Abdulla, Abdalla, Abed Allah, Abdul or Abdo.

- Technique, like procedure, is a term often confused with that of strategy. It was and is still used to mean a procedure or a strategy (Molina \& Albir, 2002). Nida (1964), a Bible translator, used the term "Technique" to mean a strategy or a procedure as in the following (addition, subtractions and alterations). He also used the term technique in his componential analysis to "identify and discriminate specific features of a range of related words as in Nida's (1964a, pp. 84-85) plotting of relationship terms (grandmother, mother, cousin, etc.) according to the values of sex (male, female), generation (the same, one, two or more apart) and lineality (direct ancestor/descendant or not). Such results are useful for a translator working with languages that have very different kinship terms". The parameter technique, however, is taken here to refer to the mechanism used by a translator to understand, interpret, analyse and propose a solution for a specific translation problem or difficulty.

\section{A Proposed Novel Methodological Framework for English-Arabic-English Translators}

This methodological framework for English-Arabic-English students and teachers of translation has been made with the following criteria and aims in mind:

1) To distinguish between the concepts of the translation parameters "method, approach, strategy, procedure and technique".

2) To standardise the approach of translating any text by using a specific sequence of steps that proceed from the global to the local and then from the paralinguistic to linguistic features of the text.

3) To maintain the most common used terms in translation theory and practice.

4) To formulate a framework to explain the mechanism of how to approach translation from the more general to more specific parameters.

5) To avoid duplication and confusion over the use of parameters "strategy, procedure or technique". I have opted to only use 'strategy' as a generic term to cover the concept of both procedure and technique. It will be used as a standardised tool or mechanism to help a translator find solutions to specific translation problems and difficulties.

Essentially, a triad methodological framework consisting of the translation parameters method, approach, and strategy, has been made. It has been set out in an order of sequential steps to achieve focus and a high degree of approximation in a translation at both macro and micro levels:

\section{Step One: Choosing one of the following methods depending on your global translation stance:}

1) Literal Method. It is strictly SL biased. It could refer to two levels of translation: "word-for-word" translation and "grammatical construction-for-grammatical construction" translation. The former is "an interlinear form of 
translation where the SL word-order is strictly preserved, the words are translated singly by their most common meanings, out of context and cultural words are translated literally. The main use of word-for-word translation is either to understand the mechanics of the SL or to construe a difficult text as pre-translation process" (Newmark, 1988, p. 45). For example, the Arabic proverb: الجار قبل الدار would be translated as 'The neighbour before the house.'

As for the latter, it replaced "word-for-word" translation during the Abbasid Age (750-1258) and the word 'literal' translation has since been used as a generic term to indicate a slightly higher level of translation than that of "word-for-word" translation (Halimah, 2017). A "literal" translation method means that both SL individual words and grammatical constructions have corresponding TL individual words and grammatical constructions. Context is also taken into consideration. In other words, the translator is to render each "SL word or phrase into an identical word or phrase in the TL with the same number, grammatical class and type of language. That is a noun is translated into a noun, one adjective into one adjective, two into two and so on and so forth" (Ghazala, 2008, p. 6). For example: 'Omar eats a red apple every morning' عمر يأكل تفاحة حمر اء كل صباح

2) Faithful Method. This is of a higher level than the literal method regarding the achievement of translation equivalence at both linguistic and non-linguistic levels. In other words, when using this method, a translator endeavours not only to reproduce "the precise contextual meaning of the original within the constraints of the TL grammatical structure" (Newmark, 1988, p. 4) but also to transfer the social, cultural and religious associations and connotations of the original text. A translator "attempts to be completely faithful to the intentions and the text-realization of the SL writer" (Ibid, p. 46). It is for these reasons, that this method is often used in the translation of religious texts as a main. For example:

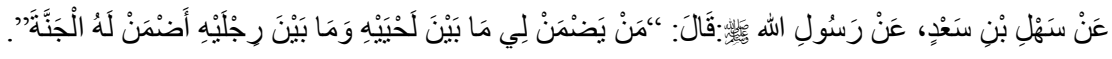

Sahel bin Saed reported that the Messenger of Allah (peace and blessings of Allah be upon him) said: "I guarantee Paradise for anyone who controls what's between his two jawbones (i.e. his tongue) and what is between his legs (i.e., his private parts)." (Halimah, 2012)

The above example shows how the faithful method can result in a stiff and conditioned sounding translation, however, one that also meets both the intentions of the SL narrator and the expectations of the TL reader; an important point to consider.

3) Semantic Method. In using this method, a translator attempts to render the exact contextual meaning of the original text as closely as the semantic and syntactic structures of the TL allow. Unlike the literal and faithful methods, "it is more flexible and tends to take account of the aesthetic value of the SL text, compromising on 'meaning' where appropriate so that no assonance, word-play or repetition jars in the finished version" (Newmark,1988:46). Furthermore, "it respects context, interprets and even explains (metaphor, for example) (Ibid:63). For example:

A. Five Syrian immigrants were shot dead yesterday.

$$
\begin{aligned}
& \text { ل لقي خمسة مهاجرين سورين مصر عهم البارحة. } \\
& \text { خمسة مهاجرين سورين قتتلوا رميا بالرصاص البارحة. (literally/faithfully translated) }
\end{aligned}
$$

B. Ali stopped smoking last week.

$$
\begin{aligned}
& \text { أقلع علي عن التددخين الأسبوع الماضي. (semantically translated with an aesthetic value) } \\
& \text { علي توقف عن التددخين الأسبوع الماضي. (literally/faithfully translated) }
\end{aligned}
$$

4) Adaptation Method. This is the 'freest' form of translation where the linguistic and cultural contexts of the SL are either completely abandoned or partially altered. It is mainly used for the translation of plays (comedies), poetry and stories, where the themes, characters and plots can often be preserved, the SL culture converted to the TL culture and the text rewritten. The adaptation of Shakespeare's play \{King Lear\} into an Arabic play called: "الثيخ الغني الأعمى وبناته الثلاثة،" (the Blind Rich Old Man \& his Three Daughters) is a good example of this method. Through adaptation, a translator essentially tends to desert the direct, linguistic context of the original text and draw on more personal conclusions in their work. For example, they could loosely translate: "I am frightened" into ابق معنا, which literally means "stay with us".

5) Free Method. Unlike the literal method, this is mainly TL oriented where a translator focuses on rendering the sense or the message of the original text into their translation rather than its form or manner. In other words, through this method a translator is free to omit what is unnecessary and add what is needed for the understanding of the translated message. An example of free translation can be found in the following stanza taken from an unpublished poem entitled "To My Son-A Letter I Cannot Write” by Judie A Halimah (2018). 
Table 7. Free translation method example

\begin{tabular}{|c|c|}
\hline $1^{\text {st }}$ Stanza of "To My Son- A Letter I Cannot Write" & A Free Method Translation \\
\hline Where nimble hands sewed, was a summer warm breeze, & في خفة ورشاقة فيب الغرزةٌ \\
\hline And a jumper sat buried with tears left to lie, & ومع الدموع أحيك هذي الكنزة \\
\hline But like the bark turned to ash with age on trees & ونسائم صبفية في دفـــــئها \\
\hline The hands that sewed began to die. & با دمعةًُ في دمعةٍ في نسجها \\
\hline \multirow{4}{*}{$* * * * *$} & مثل اللحاءٍ تحولت لرماد \\
\hline & لا لم تعـــد تلك الأيادي \\
\hline & و الموت جاء بصمتِه وخشو عه \\
\hline & لا كنزة، لتحسـاك من مصنو عهـ \\
\hline
\end{tabular}

6) Idiomatic Method. By 'idiom' we mean an affixed figurative expression which has a meaning that cannot be deduced from the denotative meanings of the words it is made up of. An example of an idiom is 'football's not my cup of tea' and as a method of translation, the idiomatic method, like the free method, is also TL oriented. For Newmark (1988:47), it is mainly concerned with the reproduction of the "message' of the original but "tends to distort nuances of meaning by preferring colloquialism and idioms where these do not exist in the original". This form of translation tends to be quite challenging as it requires the translator to not only have knowledge of the SL's idiomatic language, but also an appropriate level of knowledge, ability and skill to reproduce the original message as an idiomatic TL message, especially at a textual level. For example:

A. I watched 'Death rides a horse' movie yesterday.

$$
\text { شاهدت فيلما “، هاذم اللذات يمطتي فرسا” البارحة. }
$$

B. You may be rich and influential but you cannot walk on water.

$$
\text { قد تكون غنيا ومؤثر الكن لا تستطيع تصنع المعجزات }
$$

7) Communicative Method. This is a mainly TL reader-oriented method. It involves transferring both the exact contextual meaning and emotional aspects of the ST to the TT readers as effectively and faithfully as they are communicated to the ST readers in the first place. Essentially, the translated text should carry the same meaning and emotional force of the source text. For example,

A. Don't carry coal to Newcastle/ لا تبع الماء بحارة السقّائين

B. You know that charity begins at home. / أنت تعلم أن الأقربين أولى بالمعروف

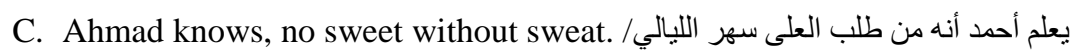

Due to a lack of space available and in order to not duplicate our discussion, other methods such as Overt/Covert translation methods suggested by Juliane House (2015) and Direct/Indirect translation methods loosely used by Vinay and Darbelnet (1995) and Ghazala, (2012) will not be tackled in this paper.

\section{Step Two: Choosing one of the following approaches depending on your local translation stance:}

1) A Domesticating Approach. This is a one-specific-issue-oriented approach where the translator decides to narrow down their scope of emphasis in translating a specific matter. Domesticating is TL and TC specific and in it "the translator tends to emphasise the TL reader's culture and value system" (Venuti, 1995, pp. 3-35). By doing so, the resulting translation is often void of any foreign trace, in terms of linguistic and cultural features. This then consequently causes the translated text to sound linguistically understandable and culturally acceptable such as, for example, in the domestication of translating and transliterating Arabic proper names like عبد الله or into Abdo/Abdul/Abdalla or Mo/Mohamed/ etc. respectively.

2) A Foreignising Approach. This approach stands in juxtaposition with domestication in terms of specificity and emphasis where it is SL and SC specific. In other words, "the translator takes the wheel making himself visible by emphasising the SL value system and linguistic features as well as cultural associations in the translated text" (Venuti, 1995, pp. 3-35). By doing so, the resulting translation often carries traces of foreignness in its linguistic and cultural features. Nevertheless, it still invites the TL reader's acceptance as it represents the SL linguistic system and cultural value of the SL people. For example, in foreignising the translation and transliteration of Arabic proper names such as عبد اله or the result would be Abdullah or Muhammad etc. because it represents the correct Arabic linguistic and cultural value system.

3) A Collaborative Approach. Collaboration in translation generally refers to the cooperation of translators, authors, publishers and translation agencies with each other to produce a translation. More specifically, it is the teamwork between participants so as to produce a translation. Halimah (2015), for example, used this approach 
when teaching poetry translation to Arabic speaking students where a group of three students and a monolingual Arabic language specialist collaborated in translating Shakespeare's 'To His Love' into Arabic poetry. This approach involved the participants not only in the initial understanding, interpretation and discussion of the Source Text, but also in the alternation of the Translated Text among themselves. For instance, student A in the group produced the first draft while the other two brainstormed to improve it. Following this, student B took up the draft produced by student $\mathrm{A}$ and spent some time working on improving it and trying to approximate it as much as possible to the original text. Student $C$ then took up the second draft to put their final creative touches on the translated text. After this laborious collaborative work, they met again to agree on the final copy of the translated text. This final copy was given to the Arabic Language Specialist to evaluate and then, in collaboration with the participants, the specialist put his poetic touches on it giving it a higher level of creative translation of poetry. This was done by turning the translated text into an Arabic Shakespearean Sonnet as follows:

Table 8. Collaboarative translation approach example

\begin{tabular}{|c|c|}
\hline $1^{\text {st }}$ Stanza of "To His Love" & Students' Collaborative Translation \\
\hline Shall I compare thee to a summer's day? & هل أقارنُ جمالَكِ بجمالِ يورٍ صيفيّ \\
\hline Thou art more lovely and more temperate: & لكنَّ سحرَ جمالِلكِ قدْ طالَهُ وفاقَهُ جمالاً \\
\hline Rough winds do shake the darling buds of May, & الرياحُ العاتيةُ قد هزتْ براعمَ مايو العزيزةً \\
\hline And summer's lease hath all too short a date; & فأيام الصيف قصبرة سريعة المضي \\
\hline \multicolumn{2}{|c|}{ The final product of the collaboration of students, teacher and the monolingual Arabic Poet! } \\
\hline 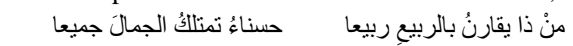 & \\
\hline ببر اعم العثقي تسيرُ سريعا & \\
\hline
\end{tabular}

4) An Eco-Cultural Approach. This approach is mainly SL eco-culture value-system specific. It generally tackles the problems and difficulties in translating ecological terms of 'Fauna', Flora', and other 'Geographical features' Peter Newmark (1988). Halimah (2018, p. 61), for example, adopted this approach to emphasise the Arabic language and culture in translating Arabic ecological terms. This approach aims to carry out both the exact denotative meaning, as well as the eco-cultural connotations, of the Arabic ecological terms into the translation with a literary or religious context. In other words, understanding an ecological term, whether it belongs to a fauna, flora or any other ecological category, is mainly determined by its eco-cultural contextual setting and by how the natives tend to perceive and interpret the term in question. This same understanding and perception should be reflected in translation as much as possible. The following is an example of how different they could be and consequently how they reflect differences in their ecological habitat, health or religious connotations.

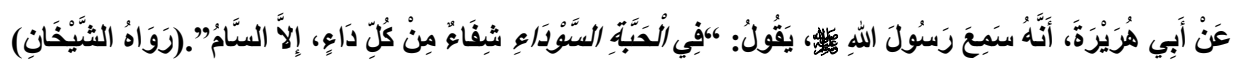

Abu Hurairah reported that he heard the Messenger of Allah (紧) saying:
A. "The Black cumin has a cure for all diseases except death."
(Bukhari \& Muslim)
B. "The Black caraway has a cure for all diseases except death."
(Bukhari \& Muslim)
C. "The fennel flower has a cure for all diseases except death."
(Bukhari \& Muslim)
D. "The nutmeg flower has a cure for all diseases except death."
(Bukhari \& Muslim)
E. "The Roman coriander has a cure for all diseases except death." (Bukhari \& Muslim)

This example shows how serious a mistake in translating an ecological term in a Prophetic hadeeth can be. It is not only a matter of translatability but rather also of ability to render an ecological concept that would carry its specific eco-cultural dimensions into another language. Therefore, I suggest the following alternative translation where not only the SL and eco-culture are emphasised but also the accuracy, clarity and religiosity of the hadeeth achieved especially with the addition of the italic word 'blessed':

Abu Hurairah reported that he heard the Messenger of Allah (蟢) saying: "The 'Blessed' Black Seed has a cure for all diseases except death." (Bukhari \& Muslim)

The above four approaches are by no means exhaustive but rather a sample of the local/regional stance which a translator takes in approaching a less global and more local translation issue.

\section{Step Three: Choosing one of the following Strategies depending on your global/local translation stance:}

This step is taken after a decision is made by a translator on which step to take from the above two and is only 
resorted to if they encounter a problem or difficulty in carrying out their translation. Essentially, the translator chooses one, two or even more of the following strategies to resolve a certain translation problem or difficulty, be it linguistic, rhetorical or cultural, depending on factors such the genre, register, text-type, purpose, intentions and readership of the translation.

1) Borrowing. In using this strategy, the translator transfers the SL word form to the TL to fill "a lexical gap or to create a certain effect" (Vinay \& Darbelnet, 1995, p. 8). In other words, when there is no equivalent counterpart for a certain word in the TL, the translator uses the same SL word but in TL transcribed letters, like in the following examples: hijab, kebab and jehad are taken from Arabic words: حجاب،كباب، بهوناد respectively and words such as انترنت، فيس بوك، تويتر ، كمبيوتر(computer, internet, Facebook, Twitter), are borrowed from English to Arabic.

2) Calque: According to Vinay and Darbelnet (1995, p. 32), this strategy is 'a special kind of borrowing'. It is used when a translator wants to replace the same expression or structure of the SL with the same expression or structure in the TL using a literal translation method. Examples of Calques can mainly be seen in the translation of common collocation and names of organisations like "Skyscrapers, مطاعم / Fast-food restaurants / منظمة الصحة العالمية World Health Organisation / عطلة نهاية الأسبوع Weekend holiday / الوجبات السريعة Organisation المنظمة التجارة العالمية etc.

3) Omission: This is a translation loss whether done consciously or unconsciously. The translator sometimes purposefully resorts to this strategy to avoid tautology or transferring unnecessary information into the Target Text by omitting certain words. For example, the bolded words si and in the Arabic version have been omitted in the English version because that they are unnecessary elements of information:

$$
\text { هذا وقد صرح وزير الصحة التركي أن أعداد المصابين بالفيروس ينخفض تدريجيا. }
$$

The Turkish Health Minister announced the infection rate of the virus has been decreasing gradually.

It must, however, be noted that while omission can be a useful strategy, the following example shows that through it a translator can risk unconsciously under translating a text. In the translation of 'Now my perished lips cannot be fed' into (هل للثفاه بأن تُطعَ جائعاً), important information is missing in the target text such as the translation of the words 'now and perished'. An accurate translation with the necessary information would be (تستطيع شفتاي التالفتان بأن تُطعَمُ الآن)

4) Addition: This is the strategy taken when a translator feels obliged to add something to the Target Text which is not in the Source Text in order to transfer its meaning more clearly and accurately for the TL reader. Here the

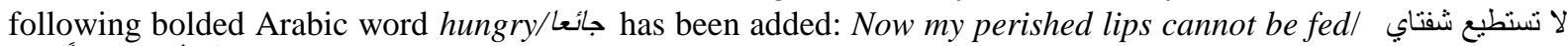
التالفتان بأن تُطعٍِ جائعاً الآن

5) Expansion. This is a strategy employed by a translator when an explicit interpretation of a ST word or expression is required in the Target Language. It often involves the Target Text being stretched out a bit to accommodate the intended meaning of the ST word/expression in the TT translation. An example of expansion is seen in how the term "irrevocable divorce" is translated as طلاق بائن لا رجعة فيه. Here the term 'irrevocable' is

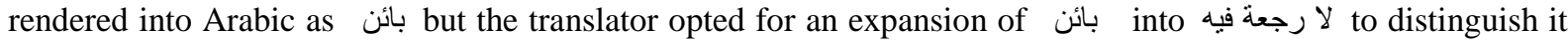
from another type of divorce (revocable divorce) in which one can return his divorcee to his custody (El-Farahaty, 2015, p. 63). Through this use of expansion, the meaning is transferred much more clearly from the Source Text into the Target Text.

6) Substitution. This is the translation strategy used when the translator needs to replace a word/a phrase in SL with another word/phrase in the TL in order for their translation to make sense, achieve its communicative effects and make an emotional impact on the TL reader. The following example shows substitution in action where the bolded summer and May in the SL and in the literal/faithful translation version A have been replaced by spring and March/الربيع وآذار in version B respectively. Halimah (2015, p. 31) 
Table 9. Substitution translation strategy example

\begin{tabular}{|c|c|}
\hline $1^{\text {st }}$ Stanza of "To His Love" by Shakespeare & Literal/Faithful Translation Version A \\
\hline Shall I compare thee to a summer's day? & هل أقارنُ جمالكِكِ بجمالِ يورِ صيفيٍّ \\
\hline Thou art more lovely and more temperate: & لكنَّ سحرَ جمالِلكِ قدْ طالَهُ وفاقَهُ جمالاً \\
\hline Rough winds do shake the darling buds of May, & الرياحُ العاتيةُ قد هزتْ براعمَ مايو العزيزةً \\
\hline And summer's lease hath all too short a date; & فأيام الصيف قصيرة سريعة المضي \\
\hline \multicolumn{2}{|l|}{ Substitution Strategy Translation Version B } \\
\hline حسناءُ تمتلائُ الجمالَ جميعا & \\
\hline بير اعمِ العشقي تسيرُ سريعا & \\
\hline
\end{tabular}

7) Transposition. This strategy 'involves replacing one-word class with another without changing the meaning of the Message' Vinay and Darbelnet, (1995, p. 36). The two translations of the English sentences below, for example, have simply employed different word classes where A uses a noun (عودته) instead of a verb (يعود) B uses a verb and an adverb instead of an adjective and a noun to express the same message.

A. He called us before he came back. اتصل بنا قبل عودنه

B. She is a creative painter. ترسم بإيداع

The above two sentences are examples of optional transposition, because we can simply translate them as follows without making any changes to their word classes.

C. He called us before he came back. اتصل بناقبل أن يعود

D. She is a creative painter إنها رسامة مبدعة

8) Modulation. Modulation entails a change of the message being translated due to a change in point of view. A negative SL expression, for example, is changed to a positive TL expression in the line it is not a strong argument' which can be translated as حجة واهية. Like transposition, it can be obligatory or optional. It is optional if منبع العلم (the fountain of knowledge) is translated as 'the root of knowledge', but obligatory if one translates (cold argument as 'weak argument' (El-Farahaty, 2015, p. 61). Another example is found in the translation of the following English sentence: There are no vacancies at the hotel.الحجز مكتمل في الفندق لدينا

9) Transliteration and Transcription. These two strategies are more or less the same when it comes to translating proper names or certain English terms. The former is a literal spelling of the English proper name in Arabic letters as it is exactly pronounced and vice versa with regard to transliterating Arabic names in English,

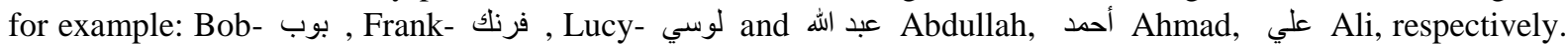
(Halimah, 2016). The latter can also be called 'transference' (تحويل/نسخ) and involves the literal spelling out of the English term in question in Arabic letters exactly how it is pronounced. This is demonstrated in the following examples: Bank (كنب) computer (كمبيوتر) Television (تلفزيون) etc. (Ghazala, 2012)

10) Naturalisation. This is a strategy based on adapting an English term to Arabic pronunciation, alphabet and grammar, or an Arabic term to English pronunciation, alphabet and grammar. This can be achieved by partially modifying its pronunciation, changing the spelling of one or more of its letters into a closely related Arabic or English one and using it in singular, plural, masculine, feminine or verb form, etc. Arabic examples are found in technology-تكنولوجياتولوجي, technologist, etc. whereas English examples are God, جهادي/jihadi the quality of the one who strives in the cause of God. As seen in the aforementioned examples, naturalised terms tend to become an integral part of the language they have been naturalised into.

The above ten strategies are by no means exhaustive but rather a sample of different strategies which a translator can refer to. Their purpose is to help a translator overcome problems and difficulties they face in translation when using global methods or local/regional approaches.

For a better understanding and application of English-Arabic-English translation parameters, I present below a novel methodological framework relevant to the needs of both students and teachers of translation in the form of a figure. The diagram below shows the relationship between a translator's global or local stance and their strategies in accordance with which they choose. 


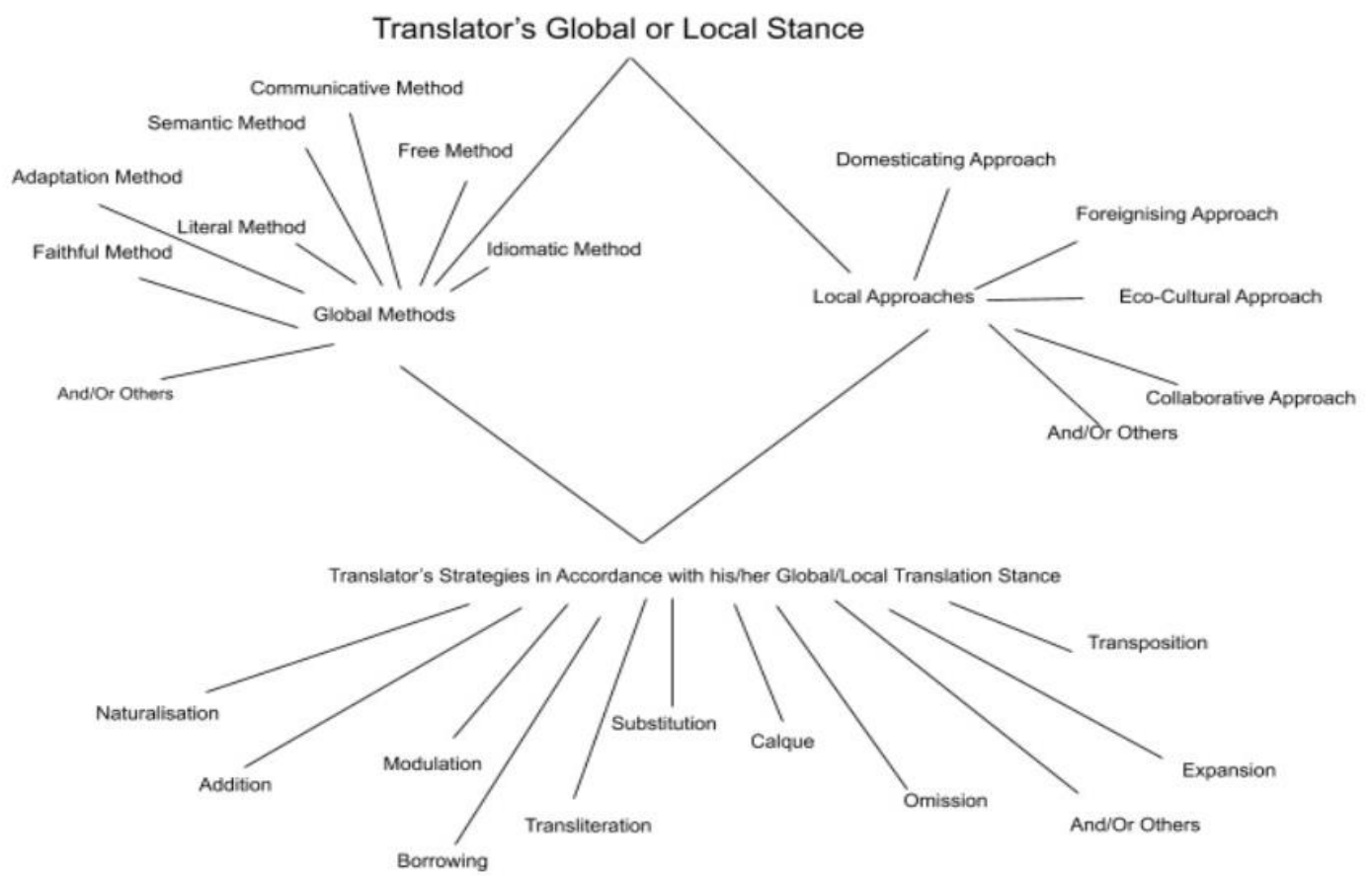

Figure 2. A novel methodological framework for the standardisation of translation parameters

\section{Conclusion}

The results of the analysis and discussion of both the questionnaire and given samples in this paper have indicated the importance of both students and teachers of translation using a methodological framework to standardise their application of the translation parameters 'method', 'approach', 'strategy', 'procedure' and 'technique'.

Those interested in translation methodology can take this English-Arabic-English Translation methodological framework further and apply it to their own native languages and different types of translation issues or with the purpose of tackling translation problems and difficulties from their own linguistic and cultural perspectives.

\section{References}

Bell, R. T. (1988). Psychological/Cognitive approaches. In M. Baker (Ed.), Routledge Encyclopaedia of Translation Studies. London \& New York: Routledge.

Catford, J. C. (1965). A Linguistic Theory of Translation. London: Oxford University Press.

Ghazala, H. S. (2014). Translation as Proplems and Solutions: A Textbook for University Students and Trainee Translators. Konooz Al-Marifa Company for Printing and Publishing, Jeddah, Saudi Arabia.

Guerra, A. F. (2012). Translating culture: problems, strategies and practical realities. Subversion, 1.

Gutas, D. (1998). Greek Thought, Arabic Culture. Oxford, UK: Routledge.

Halimah, A. M. (2012). Muhammad: The Messenger of Guidance, A Concise Introduction to His Life and Islam. International Islamic Publication House, Riyadh, Saudi Arabia.

Halimah, A. (2016). Translating Arabic Proper Names: A Foreignising Approach. International Journal of English Language and Linguistics Research, 14(2), 1-16.

Krings, H. P. (1986). Translation Problems and Translation Strategies of Advanced German Learners of French. In J. House \& S. Blum-Kulka (Eds.), Interlingual and Intercultural Communication (pp. 23-75). Tubingen: Gunter Narr.

Lörscher, W. (1992). Translation Performance, Translation Process, and Translation Strategies: A Psycholinguistic Investigation (Vol. 5). London: Rutledge: TTR: traduction, terminologie, redaction- Erudit. https://doi.org/10.7202/014625ar 
Molina, L., \& Hurtado, A. A. (2002). Translation Techniques Revisited: A Dynamic and Functionalist Approach, META, 47(4), 498-512. https://doi.org/10.7202/008033ar

Munday, J. (2001/2008). Introducing Translation Studies: Theories and Practice. London: Routledge. https://doi.org/10.4324/9780203869734

Newmark, P. (1988). A Textbook of Translation. Prentice Hall International (UK) Ltd.

Nida, E. (1964a). Toward a Science of Translating. Leiden: Brill.

Ordudari, M. (2007). Translation Procedures, Strategies and Methods. Translation Journal, 11(3).

Owji, Z. (2013). Translation Strategies: A Review and Comparison of Theories. Translation Journal, 17(1).

Venuti, L. (1995). The Translator's Invisibility : A History of Translation. London \& New york, Routledge. https://doi.org/10.4324/9780203360064

Vinay, J. P., \& Jean, D. (1995). Comparative Stylistics of French and English: A Methodolgy for Translation. Amsterdam and Philadelphia: John Benjamins. https://doi.org/10.1075/btl.11

\section{Appendix A}

\section{A Questionnaire on}

\section{How Students and Teachers of Translation tend to use Translation Parameters}

Dear Student/Teacher

The purpose of this questionnaire is to find out how you tend to use translation parameters such as "method, approach, strategy, procedure and technique" in your translation and/or teaching of translation. You are kindly requested to answer the questionnaire and return it as soon as possible. The information you give will be used for research only.

In the table below, please indicate which term you would normally use in regard to each topic when you are translating or teaching translation. Please show your choice by using $(\checkmark)$ in the relevant box needed:

\begin{tabular}{|c|c|c|c|c|c|}
\hline Translation Topics & $\begin{array}{l}\text { Method } \\
1\end{array}$ & $\begin{array}{l}\text { Approach } \\
2\end{array}$ & $\begin{array}{l}\text { Strategy } \\
3\end{array}$ & $\begin{array}{l}\text { Procedure } \\
4\end{array}$ & $\begin{array}{l}\text { Technique } \\
5\end{array}$ \\
\hline 'Word-for-word' Translation & & & & & \\
\hline Sense-for-sense Translation & & & & & \\
\hline Direct translation & & & & & \\
\hline Oblique translation & & & & & \\
\hline Literal Translation & & & & & \\
\hline Free Translation & & & & & \\
\hline 7. Semantic Translation & & & & & \\
\hline Faithful Translation & & & & & \\
\hline Communicative Translation & & & & & \\
\hline 10. Adaptation Translation & & & & & \\
\hline 11. Idiomatic Translation & & & & & \\
\hline 12. Foreignising Translation & & & & & \\
\hline 13. Domesticating Translation & & & & & \\
\hline 14. Collaborative Translation & & & & & \\
\hline 15. Arabisation Translation & & & & & \\
\hline 16. Borrowing \& Calque Translation & & & & & \\
\hline 17. Omission Translation & & & & & \\
\hline 18. Addition Translation & & & & & \\
\hline 19. Expansion Translation & & & & & \\
\hline 20. Modulation Translation & & & & & \\
\hline 21. Transposition Translation & & & & & \\
\hline 22. Substitution Translation & & & & & \\
\hline 23. Transliteration Translation & & & & & \\
\hline 24. Naturalisation Translation & & & & & \\
\hline 25. Componential Analysis Translation & & & & & \\
\hline
\end{tabular}

THANK YOU FOR COMPLETING THIS QUESTIONNAIURE 


\section{Copyrights}

Copyright for this article is retained by the author, with first publication rights granted to the journal.

This is an open-access article distributed under the terms and conditions of the Creative Commons Attribution license (http://creativecommons.org/licenses/by/4.0/). 